\title{
Impact of Stem and Yellow Rusts on Grain Yield of Bread Wheat (Triticum Aestivum L) Genotypes Under Rainfed Conditions of Ethiopia
}

\author{
Yewubdar Shewaye*, Habtemariam Zegaye, Zerihun Tadesse, Tafesse Solomon, Dawit Asnake, \\ Gadisa Alemu, Abebe Delesa, Ruth Diga, Demeke Zewdu
}

Ethiopian Institute of Agricultural Research (EIAR), Kulumsa Agricultural Research Center, Asella, Ethiopia

Email address:

yewb21@gmail.com (Y. Shewaye)

${ }^{*}$ Corresponding author

\section{To cite this article:}

Yewubdar Shewaye, Habtemariam Zegaye, Zerihun Tadesse, Tafesse Solomon, Dawit Asnake, Gadisa Alemu, Abebe Delesa, Ruth Diga, Demeke Zewdu. Impact of Stem and Yellow Rusts on Grain Yield of Bread Wheat (Triticum Aestivum L) Genotypes Under Rainfed Conditions of Ethiopia. International Journal of Bioorganic Chemistry. Vol. 6, No. 1, 2021, pp. 7-13. doi: 10.11648/j.ijbc.20210601.13

Received: January 25, 2021; Accepted: April 27, 2021; Published: May 27, 2021

\begin{abstract}
Plant diseases are among the major factors affecting the yield of wheat, especially rust diseases have historically been one of principal biotic production constraints in the world. Among the three main rusts affecting wheat, yellow rust, caused by Puccinia striiformis f. sp. tritici, and Stem rust caused by Puccinia graminis f. sp tritici are the most important disease in most wheat growing areas of Ethiopia. There are a limited number of resistant varieties available and new pathotypes that overcome the most widely deployed genes have arisen. The development of improved varieties of bread wheat (Triticum aestivum L.) has always remained a focal point for wheat breeders. Therefore, the purpose of this study was to select genotypes with good agronomic performance that have high grain yield and yield component with better rust resistance especially for stripe and stem rusts which are the major diseases in Ethiopia and to recommend the best genotypes to be released as new varieties and as an initial material in breeding. Twenty-Eight genotypes with two checks were evaluated in consecutive two years. From the twenty-eight tested genotypes almost all genotypes except one (ETBW9589) showed higher grain yield than the two standard checks (Kingbird and Ogolcho). But for the case of both rust diseases as AUDPC and CI showed that tested genotypes were exhibited different reaction responses, if we see one genotypes as an example ETBW9578 had the highest grain yield and good for yellow rust but as AUDPC showed it is very susceptible reaction response for stem rust. Generally phenotypic variation was observed for infection types, level of severity and reaction response for both diseases of the 28 tested elite bread wheat genotypes and the two standard checks. Reaction response for stem rust exhibited from susceptible (S) to Moderately resistance-moderately susceptible (M) and from immunity (0) to moderately resistance (MR) for the yellow rust. Around nine genotypes had good performance for all parameters; for grain yield and yield components and also for both rust diseases. The results of current study indicated that the genotypes had diversity regarding resistance reaction, ranging from complete resistance to susceptible. Most of the evaluated genotypes exhibited moderate resistance (MR) to moderately susceptible (MS) reactions under high disease pressure.
\end{abstract}

Keywords: Triticum Aestivum L., Puccinia Graminis, Puccinia Striiformis and Genotypes

\section{Introduction}

Wheat (Triticum aestivum L.) has a prominent position among the cereals that supplement nearly one-third of the total world population's diet by providing half of the dietary protein and more than half of the calories [8]. With the rising global population and decreasing arable land, wheat production and yield improvement became crucial. Therefore, to fulfill the food demands of an ever-growing population, the food produced in developing countries has to be enhanced by 70 per cent till 2050 [19].

Ethiopia is the largest wheat producer country in SubSaharan Africa [6]. About 5 million Ethiopian farmers produce 5.3 million tons of wheat across 1.8 million hectares 
of land under rain-fed conditions [5]. Its popularity comes from the versatility of its use in the production of a wide range of food products, such as injera, breads, cakes, pastas, etc. Wheat ranks third in area coverage and total production after teff and maize. Although the productivity of wheat has increased in the last few years in Ethiopia; it is still very low as compared to other wheat producing countries. The national average productivity is estimated to be $2.97 \mathrm{t}$ ha-1 [5]; which is by far below experimental yields of over 5 tons ha-1 [11]. So, for national productivity reduction there are different constraints from those, Plant diseases are among the major factors affecting the yield of wheat, especially rust diseases have historically been one of principal biotic production constraints in the world.

Among the three main rusts affecting wheat, stripe rust, caused by Puccinia striiformis f. sp. tritici, and Stem rust caused by Puccinia graminis f. sp tritici are the most important disease in most wheat growing areas of Ethiopia. There are a limited number of resistant varieties available and new pathotypes that overcome the most widely deployed genes have arisen. Due to stripe rust grain yield losses of 10 to $70 \%$ have been reported depending upon the cultivar grown and the environmental conditions [17]. Great losses of wheat production have been associated with stripe rust, when epiphytotics occurred under favorable conditions [18]. Under favorable conditions, stem rust can also cause yield losses of up to $100 \%$ in susceptible varieties [16].

The development of improved varieties of wheat (Triticum aestivum L.) has always remained a key point for wheat breeders all over the world [4]. Therefore, the purpose of this study was to select genotypes with good agronomic performance that have high grain yield and yield component with better rust resistance especially for stripe and stem rusts which are the major diseases in Ethiopia and to recommend the best genotypes to be released as new varieties and as an initial material in breeding.

\section{Materials and Methods}

\subsection{Experimental Plot Design for Yield Assessment}

The experimental materials consisted of 28 genotypes, in addition, two released varieties (Kingbird and Ogolcho) were used as a check. The genotypes were evaluated in alpha lattice design with three replications at four environments (Kulumsa, Asasa, Dhere and Melkasa Research sites) for two consecutive main cropping seasons (2017/18-2018/19). In both years each genotype was sown with six rows of $2.5 \mathrm{~m}$ length with $0.2 \mathrm{~m}$ space between the rows, being plot size of $3 \mathrm{~m}^{2}$. Six rows were harvested and the net harvested plot was $3 \mathrm{~m}^{2}(2.5 \mathrm{~m} \times 1.2 \mathrm{~m})$. Field management and agronomic practices were carried out as recommended for each location. The seed rate was maintained at $150 \mathrm{Kg}$ ha-1. Urea and DAP fertilizer were applied at the rate of $50 \mathrm{~kg} / \mathrm{ha}$ and $100 \mathrm{~kg} / \mathrm{ha}$, respectively. The $\mathrm{N}$ fertilizer in the form of Urea was applied at planting and tillering time (top dressing). Locations are the main variety testing site for wheat regional center Excellence and were fall in the Midland to Lowland zone (2200-1550 meter above sea level). To estimate significant differences among genotypes the data were subjected to statistical analysis by using $\mathrm{R}$ software.

\subsection{Disease Assessment}

To evaluate these genotypes for yellow and stem rust diseases have been planted at two hot spot areas Meraro and Arsi Robe for yellow and stem rust respectively. The data have been collected from hot spot areas for yellow rust from Meraro site and Stem rust from Arsi Robe by observing the spore severity on the leaves surfaces of each genotype. Host response to both rusts was recorded based on the modified Cobb scale [14]. This scale combines several infection types; resistant (R), moderately resistant (MR), moderately susceptible (MS), combination of MR and MS (M), and susceptible (S). Severity was recorded on $0-100 \%$ scale where $0 \%$ was considered as immunity while $100 \%$ was completely susceptible. The severity and field response were converted to coefficient of infection (CI) by multiplying the severity with the arbitrary constant value for field response [20, 16], where $\mathrm{R}=0.2, \mathrm{MR}=0.4, \mathrm{M}=0.6, \mathrm{MS}=0.8$, and $\mathrm{S}=1$. Field response was recorded 3 times at every 12 days interval for the case of stripe rust starting from mid of september and for stem rust starting from october upto the disease development and the crop response to the disease stop/at maturity stage.

The Area under Disease Progress Curve (AUDPC) was calculated following the method used by Wilcoxson et al. (1975).

$$
\text { AUDPC }=\sum_{i=1}^{n-1}[0.5(x i+x i+1)][t i+1-t i]
$$

Where, $x i=$ the average coefficient of infection of $i^{\text {th }}$ record, $\mathrm{Xi}+1=$ the average coefficient of infection of $\mathrm{i}+1^{\text {th }}$ record and $\mathrm{ti}+1-\mathrm{t}=$ Number of days between the ith record and $\mathrm{i}+1^{\text {th }}$ record, and $n=$ number of observations

Table 1. The pedigree information of the genotypes evaluated in four environments in 2013 and 2014.

\begin{tabular}{ll}
\hline Entry & Pedigree \\
\hline 1 & Check \\
2 & INQALAB $91 * 2 /$ TUKURU//T. SPELTA PI348599/3/2*INQALAB $91 * 2 /$ KUKUNA/4/2*KINGBIRD \#1//INQALAB 91*2/TUKURU \\
3 & SUP152/BAJ \#1 \\
4 & CHIBIA//PRLII/CM65531/3/MISR 2*2/4/HUW234+LR34/PRINIA//PBW343*2/KUKUNA/3/ROLF07 \\
5 & PREMIO/2*BAVIS \\
6 & $92.001 E 7.32 .5 /$ SLVS/5/NS-732/HER/3/PRL/SARA//TSI/VEE\#5/4/FRET2/6/SOKOLL/3/PASTOR//HXL7573/2*BAU \\
7 & SOKOLL/3/PASTOR//HXL7573/2*BAU/4/NAVJ07 \\
8 & MILAN/KAUZ//PRINIA/3/BAV92/4/BAVIS \\
\hline
\end{tabular}




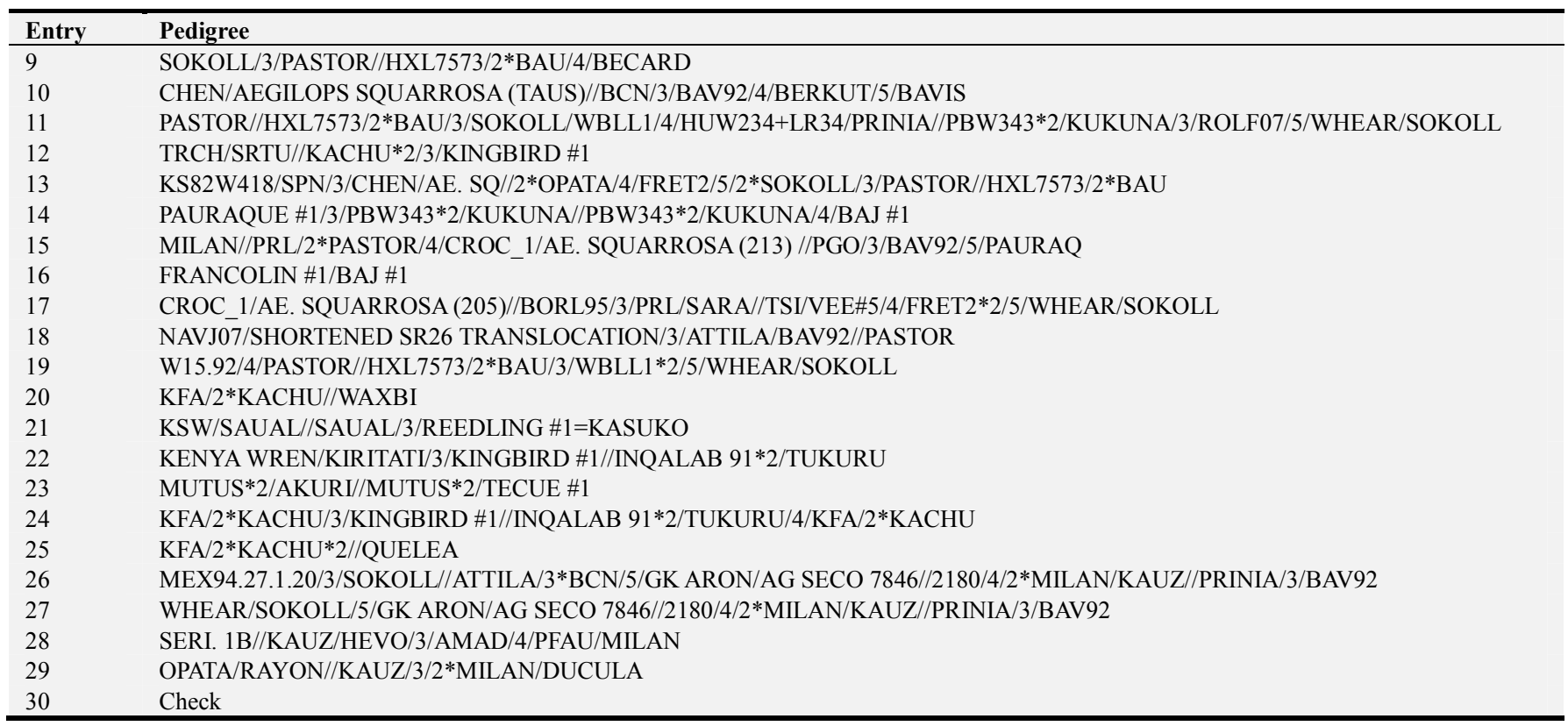

\section{Result and Discussion}

Table 2. Summary of yellow and stem rust disease parameters and grain yield under field conditions of 28 tested bread wheat genotypes.

\begin{tabular}{|c|c|c|c|c|c|c|c|c|}
\hline \multirow{2}{*}{ S. $\mathbf{N}$} & \multirow{2}{*}{ Genotype } & \multirow{2}{*}{ GYLD } & \multicolumn{3}{|c|}{ Stem Rust } & \multicolumn{3}{|c|}{ Yellow Rust } \\
\hline & & & CI & AUDPC & Response & CI & AUDPC & Response \\
\hline 1 & Kingbird & 4 & 9 & 84 & $\mathrm{M}$ & 6 & 112.5 & MSMR \\
\hline 2 & ETBW9562 & 4.2 & 18 & 345 & M & 8 & 187.5 & MRS \\
\hline 3 & ETBW9563 & 4.5 & 1.6 & 207 & MSS & 6 & 112.5 & MRMS \\
\hline 4 & ETBW9564 & 4.1 & 18 & 345 & M & 2 & 28.5 & MR \\
\hline 5 & ETBW9565 & 5.5 & 16 & 165 & MSS & 0.4 & 3 & MR \\
\hline 6 & ETBW9566 & 5.4 & 24 & 364.5 & MSS & 0.4 & 3 & MR \\
\hline 7 & ETBW9567 & 4.4 & 32 & 540 & MSS & 2 & 15 & MR \\
\hline 8 & ETBW9568 & 5.3 & 3 & 39 & M & 0.4 & 3 & MR \\
\hline 9 & ETBW9569 & 4.4 & 4 & 30 & MSS & 1 & 7.5 & MS \\
\hline 10 & ETBW9570 & 4.7 & 32 & 516 & MSS & 0 & 0 & 0 \\
\hline 11 & ETBW9571 & 4.9 & 24 & 390 & MSS & 2 & 24 & MR \\
\hline 12 & ETBW9572 & 4.9 & 8 & 78 & MSS & 18 & 322.5 & MSMR \\
\hline 13 & ETBW9573 & 5.2 & 12 & 108 & MSS & 0 & 0 & 0 \\
\hline 14 & ETBW9574 & 5 & 16 & 171 & MSS & 12 & 243 & MSMR \\
\hline 15 & ETBW9575 & 5.1 & 9 & 193.5 & M & 2 & 27 & MR \\
\hline 16 & ETBW9576 & 4.8 & 32 & 690 & MSS & 0.4 & 12 & MR \\
\hline 17 & ETBW9577 & 4.4 & 9 & 130.5 & M & 2 & 78 & MR \\
\hline 18 & ETBW9578 & 5.7 & 70 & 1665 & $\mathrm{~S}$ & 6 & 108 & MSMR \\
\hline 19 & ETBW9579 & 5 & 16 & 216 & MSS & 6 & 57 & MRMS \\
\hline 20 & ETBW9580 & 4.3 & 8 & 111 & MS & 40 & 637.5 & MS \\
\hline 21 & ETBW9581 & 5.2 & 4 & 30 & MS & 6 & 112.5 & MSMR \\
\hline 22 & ETBW9582 & 4.6 & 48 & 975 & MSS & 0.4 & 12 & MR \\
\hline 23 & ETBW9583 & 4.8 & 4 & 48 & MS & 2 & 24 & MR \\
\hline 24 & ETBW9584 & 5 & 6 & 96 & $\mathrm{M}$ & 20 & 307.5 & MS \\
\hline 25 & ETBW9585 & 5 & 6 & 96 & M & 6 & 45 & MSMR \\
\hline 26 & ETBW9586 & 4.5 & 8 & 126 & MSS & 0 & 0 & 0 \\
\hline 27 & ETBW9587 & 4.9 & 0.4 & 15 & MS & 0.4 & 12 & MR \\
\hline 28 & ETBW9588 & 4.2 & 32 & 540 & MSS & 2 & 24 & MR \\
\hline 29 & ETBW9589 & 3.5 & 90 & 2400 & $\mathrm{~S}$ & 6 & 51 & MRMS \\
\hline 30 & Ogolcho & 3.9 & 90 & 1965 & $\mathrm{~S}$ & 2 & 21 & MR \\
\hline
\end{tabular}

Area under disease progress curve (AUDPC); MR=moderately resistant; MR-MS=moderately resistant to moderately susceptible; $\mathrm{MS}=$ moderately susceptible; MS-S=moderately susceptible to susceptible; $\mathrm{S}=$ Susceptible, $\mathrm{CI}=\mathrm{Coefficient}$ of infection.

From the twenty-eight tested genotypes almost all genotypes except one (ETBW9589) showed higher grain yield than the two standard checks (Kingbird and Ogolcho).
But for the case of both rust diseases as AUDPC and CI showed some lines were exhibited susceptible reaction responses, if we see one genotypes as an example 
ETBW9578 had the highest grain yield and good for yellow response for stem rust (Table 2). rust but as AUDPC showed it is very susceptible reaction

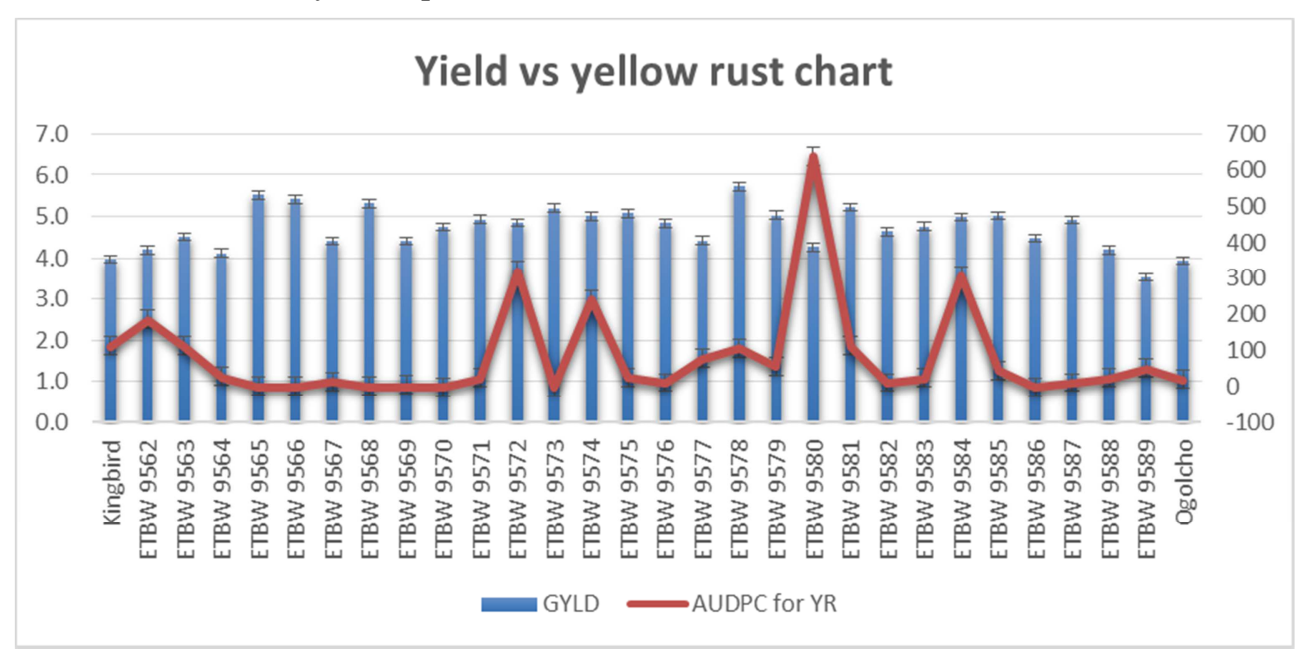

Figure 1. Grain yield and yellow rust diseases correlation.

Around nine genotypes had good performance for all parameters; for grain yield and yield components and also for both rust diseases. Most of the tested genotypes grain yield and the two rust diseases had a negative correlation except one genotype (ETBW9578), Which had highest grain yield even it had high AUDPC and CI with susceptible reaction reapnse for stem rust disease. Generally for both rust diseases more than $50 \%$ of the tested genotyepes had similar (low) cofficient of infection and AUDPC with good resistance reaction response for both diseases (Figures 1 and 2).

The AUDPC and CI values ranged from 15 to 2400 and
0.4 to 90 respectively for stem rust. While for yellow rust, AUDPC and CI values ranged from 0 to 637.5 and 0 to 40 respectively (Table 2). Data of this study revealed that, nine of the tested wheat genotypes i.e. ETBW9565, ETBW9568, ETBW9573, ETBW9575, ETBW9579, ETBW9581, ETBW9583, ETBW9585 and ETBW9587 displayed the lowest values of CI and AUDPC (less than 300 for both rust diseases). So these nine genotypes after further evaluation for other traits will be released as a new wheat varieties for the end users (commercial and/or smallholder farmers).

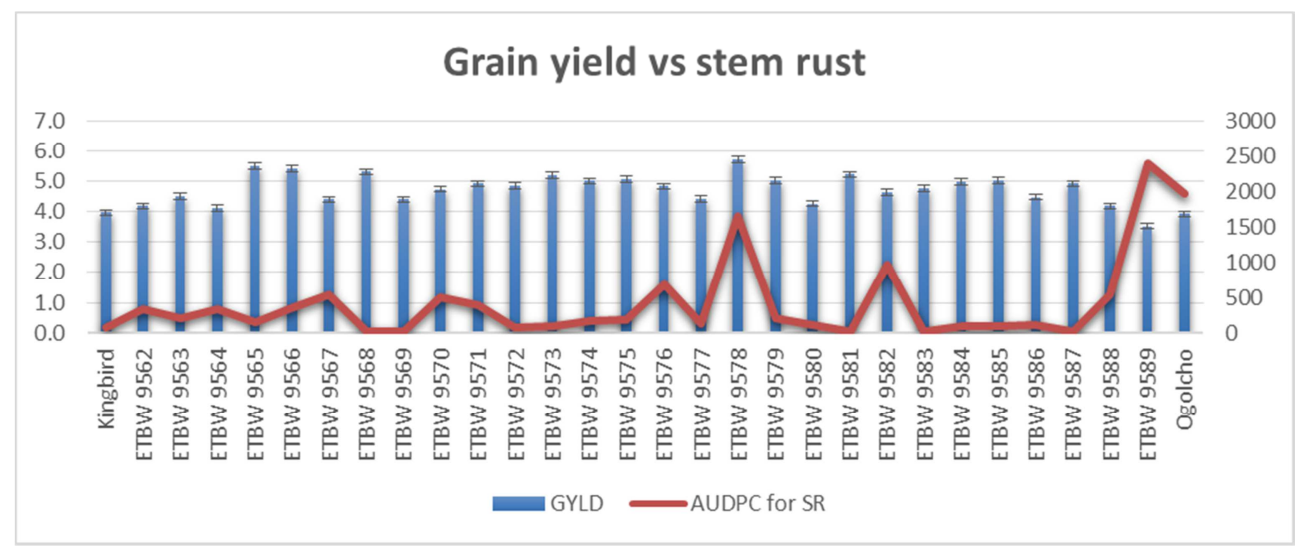

Figure 2. Grain yield and yellow rust diseases correlation.

Phenotypic variation was observed for infection types, level of severity and reaction response for both diseases of the 28 tested elite bread wheat genotypes and for the two standard checks. Reaction response for stem rust exhibited from susceptible (S) to Moderately resistance-moderately susceptible (M) and from immunity (0) to moderately resistance (MR) for the yellow rust diseases. Terminal score for stem and yellow rust ranged from 5MRR (resistant) to 90 S (highly susceptible), from (immune) to 40 s (susceptible) respectively. The higher AUDPC observed on ETBW9589 (2400) followed by Ogollcho (1965) for stem rust. Higher
AUDPC for yellow rust was 637.5 for ETBW9580 genotype.

Generally, the tested genotypes with high AUDPC and CI showed low grain yield. Whereas, wheat genotypes with the lowest values of AUDPC and CI had better grain yield.

Many researchers found that the wheat genotypes with lower values of AUDPC mostly showed the lowest yield loss; while, higher values of AUDPC caused higher grain yield loss [1]. The genotypes that have high level of resistance for both rust diseases will be used for future crossing / breeding in wheat improvement program in Ethiopia as a diseases resistance sources and the other genotypes that are high 
yielding, resistant to both diseases and good for other important traits will be released as a new varieties, so these nine genotypes are considered as new sources of resistance and after further test best performed genotypes with good disease resistance will be released as a new variety. So the Knowledge of the genetic basis of rust resistance is very essential because it will facilitate the incorporation of resistance genes into high yielding and locally adapted bread wheat cultivars and release new rust resistant varieties for large scale production by end users/ farmers.

This study was undertaken with the objectives of testing the impact of major rust diseases on grain yield of bread wheat genotypes under rainfed conditions.

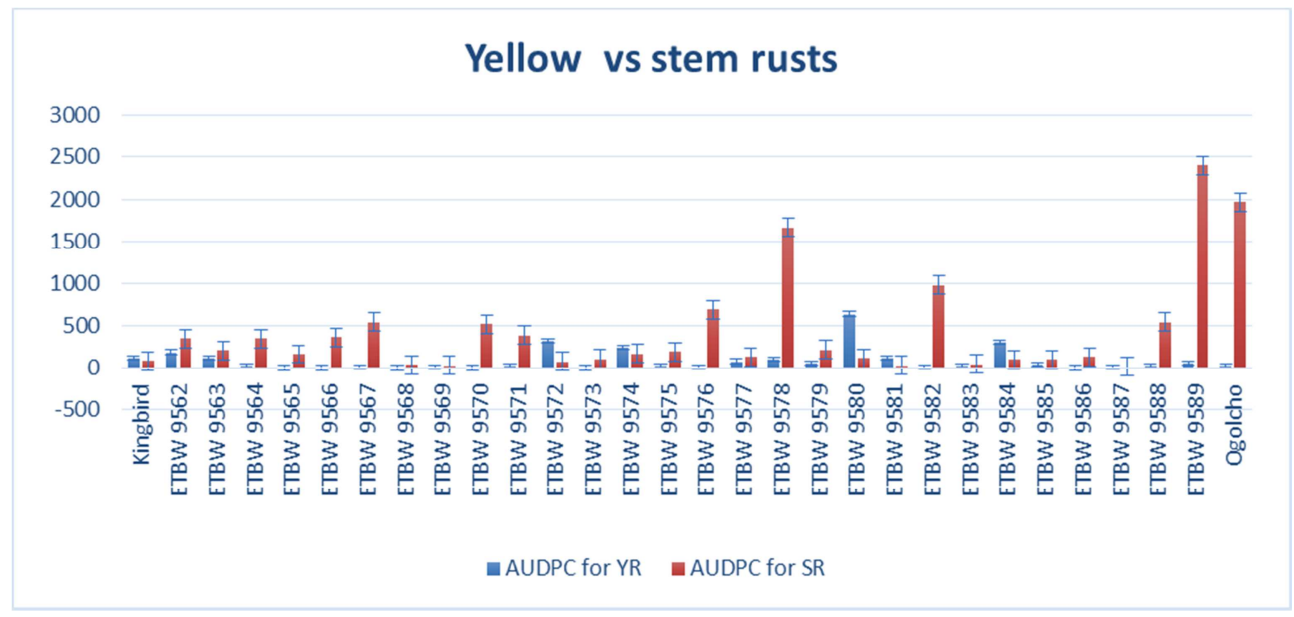

Figure 3. Yellow and stem rust correlation for each genotype.

The results of current study indicated that the genotypes had diversity regarding resistance reaction, ranging from complete resistance to susceptible. Most of the evaluated genotypes exhibited moderate resistance (MR) to moderately susceptible (MS) reactions.

Historically, stem rust epidemics have occurred throughout major wheat-producing areas, and the need to control this disease served as a cornerstone to the Green Revolution which led to the introduction of stem rust - resistant wheat varieties. Although stem rust has been well controlled in many parts of the world, forecasting models assuming the absence of durable resistance estimate that global losses would average 6.2 million metric tons per year or higher under severe epidemics The 'Digalu' race caused a devastating epidemic in Ethiopia in 2014 and a similar race has been reported in Germany [10].

For decades, stem rust has been under effective control through the use of genetic resistance. The occurrence and spread of $S r 31$-virulence races in the Ug99 race group in East Africa and other virulent races causing epidemics and localized outbreaks in Ethiopia, Europe and Central Asia, indicates that the disease is re-emerging as a threat to wheat production. Races in the Ug99 group have been detected across South, East and northern Africa, and the Middle East have the potential to reach critical wheat growing regions in the world [12].

Yellow rust is currently the most economically important wheat rust disease with yield losses reaching 100\% in susceptible cultivars. Approximately $88 \%$ of the world's wheat varieties are susceptible to yellow rust and global losses inflicted by the disease are nearly US\$ 1 billion annually [3, 21]. Wheat yellow rust has been reported in more than 60 countries and evidence suggests a significant global geographical expansion of yellow rust in the last 50 years [3].
Many race-specific rust-resistance genes have been defined genetically in wheat and are now being cloned in increasing numbers. As implied, non-race-specific resistance is defined as operating against all races of a pathogen species and is sometimes effective against multiple pathogens. Such resistance is generally quantitative, involving a partial resistance phenotype in which the pathogen growth is slowed without an obvious immune response. In wheat, this resistance is often manifested only at later stages of development and is therefore referred to as adult plant resistance (APR) [13]. More than 150 wheat rust resistance genes have been genetically defined in wheat or wild relatives, most conferring race - specific resistance [9]. At least 50 of these genes are designated Stem rust $(\mathrm{Sr})$ resistance genes that are responsible for reactions to Stem rust [9]. Developing resistant varieties combining both allstage resistance and partial resistance determined by race specific and minor genes, respectively, is a priority research area for breeders in Ethiopia. Varieties with combination of resistance genes could be more durable and more effective than varieties with sole all-stage or adult plant resistance types [2]. As a general from this study variation for yield, yield component and disease resistance for both rusts have been observed so the genotypes that are best for all parameters (yield and yield component disease resistance) will be release as new varieties after further test, but genotypes that exhibited resistance reaction response for disease and showed low grain yield will be used for developing resistance line through crossing.

\section{Conclusion}

Durable rust resistance mechanism in wheat is 
accomplished through incorporation of partially resistant minor genes which seems to be more appropriate and important solution for sustainable wheat production. Response of wheat germplasms along with grain yield and yield components indicated the presence of inverse relation with the disease level. Breeding disease resistance genotypes is a continuous and key process for the plant breeder through pyramiding/adding new effective genes to their breeding materials. The present research deals new sources of resistance that can be incorporated into wheat to escape heavy yield losses wreaked by the two important rust diseases (yellow and stem).

This research' results clearly show that grain yield potential with diseases resistance continues to increase through breeding, High grain yield potential was also successfully combined with high levels of adult plant resistance to wheat rusts. So, the major strategy for the management of rust diseases in Ethiopia would remain focused on the development of resistant varieties. Besides, plant breeder's cooperation with pathologists should be encouraged, appreciated as well as accounted for to continuously monitor rust situation and evolve resistant varieties to ensure food security.

\section{Acknowledgements}

Authors are grateful to MERCI and DGGW projects and Ethiopian Institute of Agricultural Research (EIAR) for financial support. we also highly appreciate and acknowledge Kulumsa Agricultural Research Center and other collaborating centers at Regional and Federal Research Institutes for provision of facilities and implementation of the experiment.

We also appreciate and thank Mr. Niguse Degefa, Ms Banchi Sime, Mr Wedajo Teji, Mr Mamuye Tesema, Ms Nedhi Sory and Ms Etenesh for field data collection and laboratory work.

\section{References}

[1] Atef Shahin, Mamdouh Ashmawy, Walid El-Orabey, Samar Esmail. Yield Losses in Wheat Caused by Stripe Rust (Puccinia striiformis) in Egypt. American Journal of Life Sciences. Vol. 8, No. 5, 2020, pp. 127-134. doi: 10.11648/j.ajls.20200805.17.

[2] Bekele Hundie, Fikirte Yirga, Daniel Kassa, Endale Hailu, Tamirat Negash, Tsegaab Tesfaye, Netsanet Bacha, Yewubdar Shewaye, Getaneh Woldeab, Habte Zegaye, Zerihun Tadesse, Bedada Girma. Evaluation of Advanced Bread Wheat Lines for Field and Seedling Resistance to Stem Rust (Puccinia graminis f. sp. tritici). American Journal of Biological and Environmental Statistics. Vol. 4, No. 2, 2018, pp. 74-82. doi: 10.11648/j.ajbes.20180402.14.

[3] Beddow, J. M., Pardey, P. G., Chai, Y., Hurley, T. M., Kriticos, D. J., Braun, J.-C., et al. (2015). Research investment implications of shifts in the global geography of wheat stripe rust. Nat. Plants 1: 15132. doi: 10.1038/nplants.2015.132.
[4] Brown, J. K. and Hovmøller, M. S. (2002). Aerial dispersal of pathogens on the global and continental scales and its impact on plant disease. Science, 297: 537-541.

[5] (CSA) Central Statistical Agency agricultural Sample Survey (2020) Volume Ireport On area And Production Of Major Crops (Private Peasant Holdings, Meher Season) Addis Ababa April, 2020587statistical Bulletin, Addis Ababa, Ethiopia.

[6] FAOSTAT (2018) Food and agricultural data. Resistance along with grain yield. Ann. of Agric. Sci., 60 (1): 29-39.

[7] Hasan, M. A.; Abu Aly, A. A. and El-Shehawy, Amal E. A. 2012. Losses in grain yield due to leaf rust, caused by Puccinia triticina Eriks. J. Plant Protec. and Pathol., Mansoura Univ., 3 (9): 959-966.

[8] Kasana, B. S., Singh, A. K., Tomar, R. K. S. and Rikhari, Y. C. 2016. Evaluating the performance of wheat varieties under late sown irrigated condition in Bundelkhand zone. International Journal of Applied and Pure Science and Agriculture, 1 (7).

[9] McIntosh, R. A., Dubcovsky, J., Rogers, W. J., Morris, C., Appels, R., Xia, X. C. 2011. CATALOGUE OF GENE SYMBOLS FOR WHEAT: 2013 SUPPLEMENT, KOMUGI Integrated Wheat Science Database http://www.shigen.nig.ac.jp/wheat/komugi/genes/macgene/su pplement2011.pdf.

[10] Melania Figueroa, Kime. Hammond-Kosack and Peter S. Solomon. 2018. A Review of Wheat Diseases a Field Perspective. Molecular Plant Pathology (2018) 19 (6), 15231536. Doi: 10.1111/Mpp.12618.

[11] Mengistu Mitiku, Netsanet Bacha Hei and Merkuz Abera. 2018. Characterization of Slow Rusting Resistance Against Stem Rust (Puccinia graminis f. sp. tritici) in Selected Bread Wheat Cultivars of Ethiopia. Advances in Crop Science and Technology. DOI: 10.4172/2329-8863.1000389.

[12] Olivera Firpo, P. D., Newcomb, M., Flath, K., Szabo, L. J., Carter, M., Luster, D. G., et al. (2017). Characterization of Puccinia graminis f. sp. tritici isolates derived from an unusual wheat stem rust outbreak in Germany in 2013. Plant Pathol. 66, 1258-1266. doi: 10.1111/ppa.12674.

[13] Periyannan S, Milne RJ, Figueroa M, Lagudah ES, Dodds PN (2017) An overview of genetic rust resistance: From broad to specific mechanisms. PLoS Pathog 13 (7): e1006380. https://doi.org/10.1371/journal.ppat.1006380.

[14] Peterson, R. F., A. B. Champbell, and A. E. Hannah. 1948. A diagrammatic scale for estimating rust intensity of leaves and stem of cereals. Can. J. Res. 26: 496-500. doi: $10.1139 / \mathrm{cjr} 48 \mathrm{c}-033$.

[15] Roelfs, A. P. 1985a. Epidemiology in North America. In A. P. Roelfs \& W. R. Bushnell, eds. The cereal rusts, vol. 2, Diseases, distribution, epidemiology, and control, p. 403-434. Orlando, FL, USA, Academic Press.

[16] Roelfs A, Singh R, Saari E. Rust Diseases of Wheat. Concepts and methods of disease management. Mexcio, D. F. CIMMYT; 1992 Safar Ali Safavi. 2015. "Effects of yellow rust on yield of race-specific and slow rusting resistant wheat genotypes". J. Crop Prot. Vol. 4 (3)- DOI: 10.13140/RG.2.1.4594.8647.

[17] Safar Ali Safavi. 2015. "Effects of yellow rust on yield of race-specific and slow rusting resistant wheat genotypes". J. Crop Prot. Vol. 4 (3)- DOI: 10.13140/RG.2.1.4594.8647. 
[18] Sebei Abdennour, Ferjaoui Sahbi, and Bchini Houcine 2018. "Yellow Rust Effects on Grain Yield, and Yield Components of Some Spring Bread Wheat Cultivars under Rainfed Conditions." World Journal of Agricultural Research, vol. 6, no. 2: 65-69. doi: 10.12691/wjar-6-2-5.

[19] Semenov MA, Stratonovitch P, Alghabari F, et al. 2014. Adapting wheat in Europe for climate change. J Cereals Sci; 59 (3): 245-256.
[20] Stubbs, R. W. (1988). "Pathogenicity analysis of yellow (stripe) rust of wheat and its significance in a global context," in Breeding Strategies for Resistance to the Rusts of Wheat, eds N. W. Simmonds and S. Rajaram (Mexico: CIMMYT D. F.), 23-38.

[21] Wellings, C. R. 2011. Global status of stripe rust: a review of historical and current threats. Euphytica 179: pp 129-141. 